\title{
A Kind of Creative Design for Coin Sorting Mechanism based on Archimedes Double Helix
}

\author{
Pan $\mathrm{Yi}^{1}$, Zou Yu ${ }^{1}$, Sun Peiqing ${ }^{1}$ \\ ${ }^{1}$ Wuhan Institute of Shipbuilding Technology, Wuhan 430050, China
}

Keywords: Archimedes double helix; Sorting of coins; Creative Design

\begin{abstract}
Coin, as a very important part of the financial system, has been paid great attention and widely used in our daily life. This paper introduces a kind of creative coin sorting mechanism design based on Archimedes double helix, adopting photoelectric sensor to count classification. It abandoned the traditional vibrating or partial time selection model, and finally realizes the efficient sorting inventory of a large number of coins. Its feature is that it can realize continuous type of sorting classification and counting with a larger amount per unit of time. The product mainly adopts mechanical structure and additional simpler circuit control for a low manufacturing cost.
\end{abstract}

\section{Introduction}

As the global economy continues to grow steadily, large denomination currency electronization and small denomination currency coin are the trend of currency issue in the world. With the issue of the fifth edition of RMB in China, coins (less than 10 yuan) have become a trend, and the amount of coins will be greatly increased ${ }^{[1]}$. However, due to the imperfection of coin sorting technology, many industries (banks, supermarkets, public transport companies, large retail enterprises, etc.) still use inefficient and high error rate to calculate coins by hand. Due to the large cost of manual separation of coins, small profit, no point and many errors, it is urgent to use a device to classify and count coins quickly.

\section{Overall framework of system design}

The sorting system of coins is divided into two parts: sorting and counting. The sorting parts include mechanical classification device, mechanical transmission mechanism, frame, motor drive and deceleration device. The counting section includes the counting sensor and the drop box. In order to realize the selection and technical function of the coin, the screening principle is mainly based on the size of the aperture. Through a gear reducer, the motor is transmitted to four plates, and the four screen plates are screened by one yuan coin, the big ten-cent coin, the fifty-cent coin and the small ten-cent coin. The aperture on the plate is also slightly larger than the standard diameter of various coins. It is able to screen the coins delamination well, and we use the double helix method of the Archimedes helix line to speed up the screening effect of the coin and improve the efficiency of the coin screening. Using UG software modeling, as shown in Figure 1.

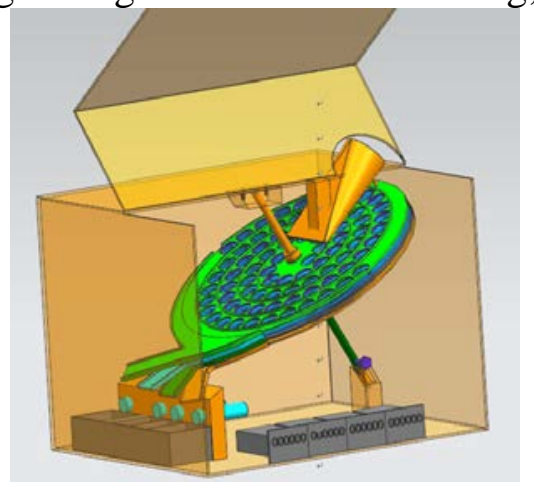

Figure 1. UG system model 


\section{Part design of sorting device}

\subsection{Design of Archimedes double helix sorting mechanism}

In the design of the coin sorting module, four layers of disc structure with double helix are used. Each layer is a sieve plate made of aluminum plate. The thickness of the plate is $6 \mathrm{~mm}$, and the diameter is $302 \mathrm{~mm}$. The Archimedes double screw with a height of $3 \mathrm{~mm}$ and a width $2 \mathrm{~mm}$ is processed on the plate by using CNC. According to the size of four coins, a series of sieve holes of the corresponding size are processed on the drying tray adjacent to the two helices. The four layers have adopted the structure of this Archimedes helix, which can greatly improve the screening effect of the coin. In addition, the disc and the horizontal direction have an angle of 30 degrees. It can smooth the coins out of the slideway and flow to the slideways of their respective layers.

The whole coin sorting module is divided into four coin separation zones by using four layers of screen plates. The distribution of the diameter of each screen mesh is shown in Figure 2. The coin is placed in the funnel 1, the funnel is underneath the flat shape opening, forcing the coin to enter the separation area horizontally, in the separation area, with the rotation of the four layer disk structure, the coin flows in the channel sandwiched between the two helix, and the first separation of the coin is realized through the one yuan coin screen plate 2. At the same time, the separated one yuan coins gradually flow outward and eventually leave the screen plates from the two outlet of the double helix and fall into the flow path $6^{[2]}$. The fifty-cent coin, ten-cent coin (big and small) enter the second separation area, and the second separation is achieved through the big ten-cent coin screen 3 . The small ten-cent coin enters the fourth separation area, and the ten-cent coin screen plate 5 does not have sieve hole. At this point, the coins of each kind of coin are sorted in the separate regions moving in the way of double helix and falling into the channels of their respective layers.

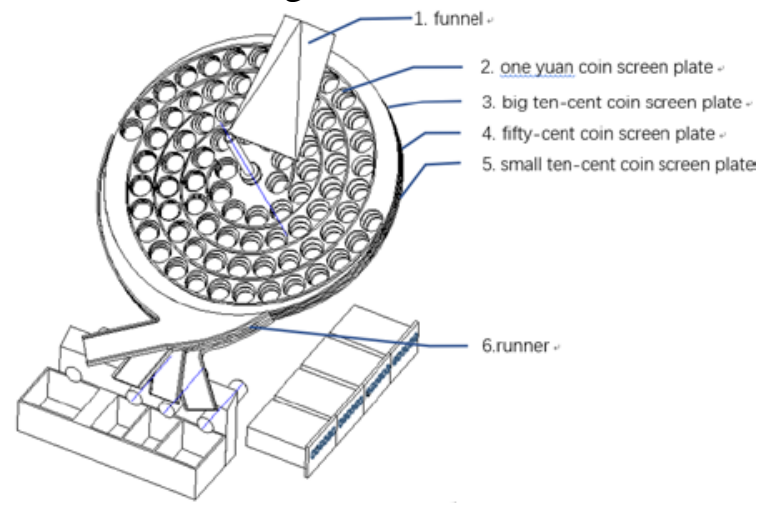

Figure 2. Archimedes double helix sorting module

\subsection{Archimedes helix calculation}

The standard polar coordinate equation of the Archimedes helix line: $R(\theta)=a+B \theta$ ), in the formula: B - Archimedes helix coefficient $\mathrm{mm} /$ degrees, indicating the increase (or decrease) of the pole diameter at 1 degrees of rotation; $\theta$ - polar angle, unit degree, representing the total degree of the rotation of the Archimedes helix; a - the pole diameter when $\theta=0$ degrees. Changing the parameter a will change the shape of the helix, and B controls the distance between the helices, usually as a constant. The Archimedes helix has two helix lines, one theta $>0$ and the other theta $<0$. The two helixs are connected smoothly at the pole. Take one of them to turn 90 degrees /270 degrees to get the mirror, which is another helix.

The Archimedes helix is used on the disc. Its main calculation is as follows:

$\mathrm{a}=10$ (refers to the rotation of one X Y Z mobile 10 units) helix single spacing $\mathrm{a}=$ spacing $/ 360$ degree

$\mathrm{t}=1$ constant

$\theta=t * 360 * 5$ (5 refer circle number)

$\mathrm{r}=\mathrm{a} * \theta$

$\mathrm{xt}=\mathrm{r}^{*} \cos \theta$

$y=r^{*} \sin \theta$ 

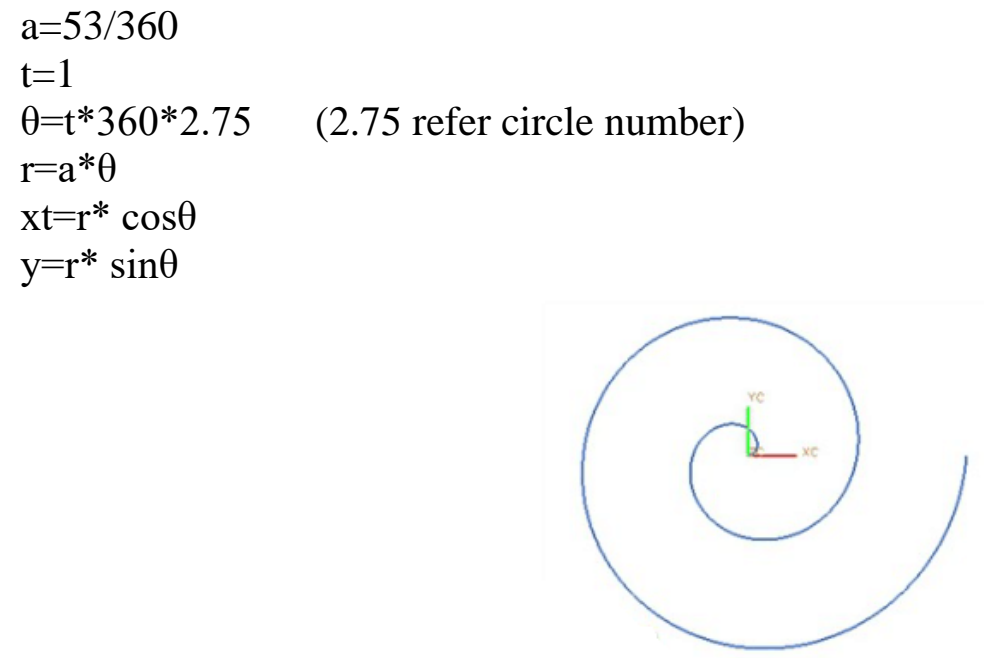

Figure 3. Archimedes helix

\subsection{Gear drive decelerator}

This mechanism uses gear transmission, as shown in Fig. 4, after several pairs of gear deceleration devices, the power of the motor is transmitted to the disk. The gear transmission of the deceleration gear is a five stage transmission, taking its modulus $m=0.1$, the main parameter formula is: $\mathrm{D}=\mathrm{mz} ; \mathrm{a}=(\mathrm{mz} 1+\mathrm{mz} 2) / 2 ; \mathrm{i}=\mathrm{Z} 1 / \mathrm{Z} 2$.

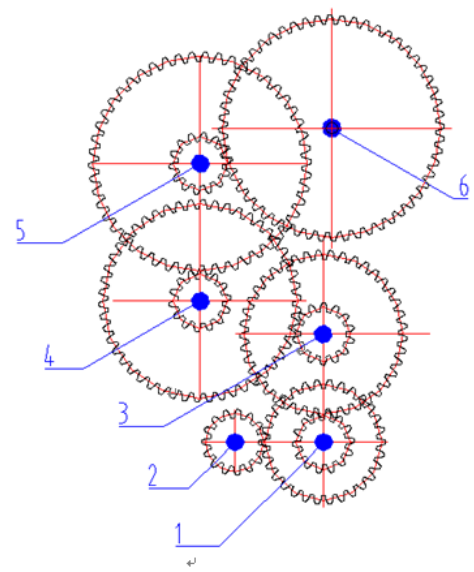

Figure 4. gear reducer

Determine the specific size:

$\mathrm{d} 1=\mathrm{mz} 1=0.1 \times 15=1.5 \mathrm{~mm}$

$\mathrm{d} 2=\mathrm{mz} 2=0.1 \times 30=3.0 \mathrm{~mm}$

$\mathrm{d} 3=\mathrm{mz} 3=0.1 \times 14=1.4 \mathrm{~mm}$

$\mathrm{d} 4=\mathrm{mz} 4=0.1 \times 41=4.1 \mathrm{~mm}$

d5 $=\mathrm{mz} 5=0.1 \times 14=1.4 \mathrm{~mm}$

d6 $=\mathrm{mz} 6=0.1 \times 50=5.0 \mathrm{~mm}$

$\mathrm{d} 7=\mathrm{mz} 7=0.1 \times 1.4=1.4 \mathrm{~mm}$

$\mathrm{d} 8=\mathrm{mz} 8=0.1 \times 50=5.0 \mathrm{~mm}$

$\mathrm{d} 9=\mathrm{mz} 9=0.1 \times 1.4=1.4 \mathrm{~mm}$

$\mathrm{d} 10=\mathrm{mz} 10=0.1 \times 56=5.6 \mathrm{~mm}$

Gear ratio: $\mathrm{i}=(\mathrm{z} 2 / \mathrm{z} 1) \times(\mathrm{z} 4 / \mathrm{z} 3) \times(\mathrm{z} 6 / \mathrm{z} 5) \times(\mathrm{z} 8 / \mathrm{z} 7) \times(\mathrm{z} 10 / \mathrm{z} 9)=298$

\section{Design of counting device}

We choose a photoelectric counter with a model of ATK11-6H. The detector has a 10-70cm 
distance and can detect the number of coins accurately. The angle between the outer disk and the flow path assembly and the horizontal direction is 30 degrees. The coin slips and falls into their respective coin receiving box after entering the respective flow passages and sets the sensor probe between the coin receiving box and the channel mouth. The coin falls into the receiving box and counts and displays the number of each currency on the quantity counter.

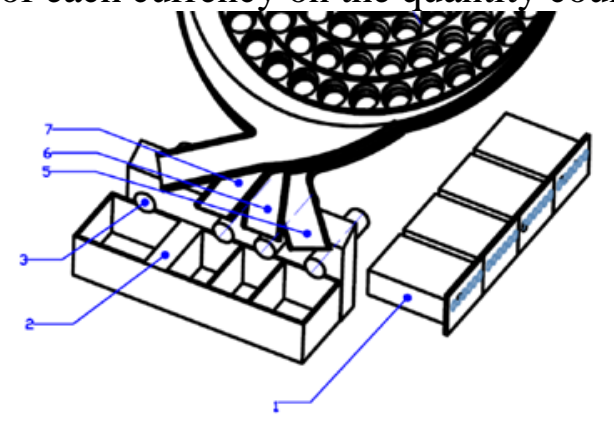

1- quantity counter; 2- coin box; 3- sensor probe; 4, 5, 6, 7- flow path.

Figure 5. counting device

\section{System test}

The four kinds of coins in the main circulation are repeated repeated tests. The test is divided into two modules: coin classification and coin counting detection. The test results are shown in Table 1.

Table 1. test results

\begin{tabular}{|c|c|c|c|c|c|c|c|c|c|c|c|c|}
\hline \multirow{2}{*}{$\begin{array}{c}\text { Test } \\
\text { times } \\
\text { Face } \\
\text { value } \\
\text { of } \\
\text { coins }\end{array}$} & \multicolumn{4}{|c|}{ Test 1} & \multicolumn{4}{|c|}{ Test 2} & \multicolumn{4}{|c|}{ Test 3} \\
\hline & $\begin{array}{c}\text { one } \\
\text { yuan }\end{array}$ & $\begin{array}{l}\text { big } \\
\text { ten-c } \\
\text { ent }\end{array}$ & $\begin{array}{l}\text { fifty- } \\
\text { cent }\end{array}$ & $\begin{array}{c}\text { small } \\
\text { ten-ce } \\
\text { nt }\end{array}$ & $\begin{array}{c}\text { one } \\
\text { yuan }\end{array}$ & $\begin{array}{c}\text { big } \\
\text { ten-ce } \\
\text { nt }\end{array}$ & $\begin{array}{c}\text { fifty-c } \\
\text { ent }\end{array}$ & $\begin{array}{c}\text { small } \\
\text { ten-cen } \\
\text { t }\end{array}$ & $\begin{array}{c}\text { one } \\
\text { yuan }\end{array}$ & $\begin{array}{l}\text { big } \\
\text { ten-ce } \\
\text { nt }\end{array}$ & $\begin{array}{c}\text { fifty-c } \\
\text { ent }\end{array}$ & $\begin{array}{c}\text { small } \\
\text { ten-ce } \\
\text { nt }\end{array}$ \\
\hline $\begin{array}{c}\text { Input } \\
\text { number }\end{array}$ & 3 & 3 & 3 & 3 & 5 & 7 & 10 & 12 & 10 & 12 & 15 & 20 \\
\hline $\begin{array}{c}\text { First } \\
\text { test }\end{array}$ & 3 & 3 & 3 & 3 & 5 & 7 & 10 & 12 & 10 & 12 & 15 & 20 \\
\hline $\begin{array}{c}\text { Second } \\
\text { test }\end{array}$ & 3 & 3 & 3 & 3 & 5 & 7 & 10 & 12 & 10 & 12 & 15 & 20 \\
\hline $\begin{array}{c}\text { Third } \\
\text { test }\end{array}$ & 3 & 3 & 3 & 3 & 5 & 7 & 10 & 12 & 10 & 12 & 15 & 20 \\
\hline $\begin{array}{l}\text { Correct } \\
\text { rate }\end{array}$ & $100 \%$ & $100 \%$ & $100 \%$ & $100 \%$ & $100 \%$ & $100 \%$ & $100 \%$ & $100 \%$ & $100 \%$ & $100 \%$ & $100 \%$ & $100 \%$ \\
\hline
\end{tabular}

\section{Conclusion}

The device is designed by the innovative mechanism of Archimedes double helix, which greatly improves the efficiency of the selection of the coin. The operation of the mechanism is separated from the common vibrating screen structure on the market. The noise and vibration of the mechanism are greatly reduced, and the uninterrupted screening, classification and counting can be realized. ${ }^{[3]}$ The experimental results show that the system realizes the classification of coins, the accuracy of the system can reach $100 \%$. In the later improvement, the system can be added to the system with a higher value of popularization and application.

\section{Acknowledgement}

Project fund: Wuhan Institute of Shipbuilding Technology key project support, Project No.: 2017z01 


\section{References}

[1] CNC machining of Chen $\mathrm{Xu}$ Archimedes spiral parts. Xi'an: Northwestern Polytechnical University press,.2005

[2] Wang Gang, Song Yingjie, Wang Xindi, Tan Fengjuan. Design of automatic checking and clearing system for coins based on STC89C52 [J]. Journal of Baicheng Normal University, 2018, 32 (3): $1-8$

[3] Pan Yi, Wuhan Institute of Shipbuilding Technology. A double spiral coin separator [P]. China: ZL 201620892157.42017 February 8th. 